\title{
Urban Total Factor Productivity: Does Urban Spatial Structure Matter in China?
}

\author{
Haidong Yu ${ }^{1}$, Yong Liu ${ }^{1, *}$, Juanjuan Zhao ${ }^{2}$ and Gen $\mathrm{Li}^{1}$ \\ 1 School of Economics, Sichuan University, Chengdu 610065, China; 2017321010020@stu.scu.edu.cn (H.Y.); \\ 2015321010012@stu.scu.edu.cn (G.L.) \\ 2 College of Horticulture and Landscape Architecture, Southwest University, Chongqing 400715, China; \\ juanjuanzhao@swu.edu.cn \\ * Correspondence: yonghopeliu@scu.edu.cn
}

Received: 2 December 2019; Accepted: 22 December 2019; Published: 25 December 2019

check for updates

\begin{abstract}
With the rapid development of urbanization in China, urban spatial form has increasingly gained research attention. In this study, the DEA (data envelopment analysis)-Malmquist index model and a panel data model are used to examine the relationship between the urban spatial form and total factor productivity (TFP) of 30 provincial cities in China. Our method of measuring urban spatial form is different from the current entropy method, but we use remote sensing GIS (Geographic Information System) technology to measure the relevant data on urban compactness and urban elongation. The average values of urban compactness and urban elongation first rise, then fall, and then rise again, and there are alternate situations of urban compact development and urban sprawl and expansion. Furthermore, there is a significant positive correlation between urban compactness and TFP. Therefore, cities with high urban compactness can promote TFP. In addition, there is a significant negative correlation between urban extension rate and TFP, indicating that an increase in urban elongation has a restraining effect on TFP. Finally, the average TFP of each city shows a fluctuating trend of rising first and then declining, which is determined mainly by technological change and efficiency change. These results are expected to provide a scientific basis for the development of urban agglomerations in China.
\end{abstract}

Keywords: urban compactness; urban elongation; urban TFP; DEA-Malmquist index; panel data model

\section{Introduction}

With the rapid development of China's economy, the country's total economic output ranks second in the world. With the acceleration of industrialization, China's urbanization has been characterized by a low starting point and rapid development. According to data from the "National New Urbanization Plan 2014" [1], from 1978 to 2013, the permanent population of cities and towns increased from 170 million to 730 million, the urbanization rate increased from $17.9 \%$ to $53.7 \%$, and the annual average increase of urbanization rate was 102 percentage points. In addition, the number of cities increased from 193 to 658, and the number of newly created towns increased from 2173 to 20,113. Infrastructure related to water, electricity, roads, gas, and information networks has significantly improved, as has the level of public services, such as education, medical treatment, culture, sports, and social security. The aforementioned policy document also proposes the idea of compact cities and shares relevant instructions for its implementation. Both Lewin [2] and Kotharkar et al. [3] believe that measuring urban form and compactness is particularly important for understanding urban spatial structure and sustainable development. 
As the population and its level of activity are the main drivers of urban economic development, urban spatial structures may be closely related to urban economic development and its efficiency. The theory of urban economics holds that a good urban form can improve labor productivity by accelerating the flow of factors while the theory of scale economy points out that economic agglomeration is the cause of the formation of urban centers. Therefore, the development and evolution of urban spatial structure is also the process of changing economic performance.

In terms of urban spatial structures and economic development, the results of Sveikauskas [4] and Beeson [5] show that the output level of an urban economy increases by $5 \%$ to $15 \%$ with the doubling of the urban population. Qi et al. [6] concluded that the industrial compactness of an urban agglomeration was positively correlated with the degree of urban agglomeration development. Lee and Gordon [7] used the employment data of 79 metropolitan areas in the United States in the 1990s and the 21st century to analyze the relationship between the spatial structure of large cities and economic growth. Huang and Dong [8] found that the spatial pattern of urban compactness in China is the highest in the east, followed by the central region, and finally the western region. The spatial pattern of China's regional economic development also follows the same order. Thus, the spatial pattern of urban compactness is highly consistent with that of regional economic development.

In terms of urban spatial structure and economic efficiency, Wang et al. [9] found that the improvement of urban compactness is conducive to improving the total factor productivity (TFP) of cities. Cervero [10] also believes that labor productivity is proportional to urban size. Salvati's [11] study found that compact cities have higher growth rates than do decentralized cities. After controlling for other factors, Meijers and Burger [12] found that the balanced distribution of the urban population in different cities in the United States had higher labor productivity. Sun et al. [13] explored the relationship between spatial structure and economic performance for 107 metropolitan areas, 31 mega-cities, and 287 prefectural-level cities in China. They found that for mega-cities, a multicenter is more conducive to economic development, but for cities above the prefectural level, a single-center has higher labor productivity. Therefore, it is concluded that the optimum urban spatial structure is "single center-multicenter-single center" according to the increasing size of a city. In addition, the improvement of urban traffic is also related to urban spatial structures and urban efficiency. Empirical results from Hao et al. [14] show that the improvement of traffic can effectively promote urban compactness, and cities with high urban compactness tend to have higher urban productivity. Traffic not only affects urban productivity directly but also indirectly by affecting urban compactness.

Globally, economic growth is one of the most important goals of a country or region. The source of economic growth mainly involves two aspects: factor input growth (capital and labor) and technological progress. The TFP mentioned in this paper is the additional production efficiency that can be achieved under the condition of a fixed input level of various factors of production. In the measurement of TFP, the main measurement method at present is the production frontier method. This method can effectively decompose the growth of TFP into technical progress, technical efficiency, and scale efficiency. The commonly used frontier analysis methods include the nonparametric data envelopment analysis (DEA) and the parametric stochastic frontier analysis (SFA). Research using DEA includes Fare et al. [15], Kumar and Russell [16], Lall et al. [17], and Kruger [18]. Specific to China, nonparametric DEA methods are mainly studied by Lin and Liu [19], Zheng and Hu [20], Yan and Wang [21], Gao et al. [22], and Wang et al. [23]. This study also uses the DEA method to measure production efficiency at the city level.

Based on the literature review, this study uses remote sensing data to measure urban spatial forms and uses it as an influencing factor to investigate TFP. What are urban spatial form and urban efficiency? What is the relationship between them? We need to draw conclusions through empirical research. Therefore, this study mainly focuses on (1) the design of an urban spatial form evaluation index, (2) using the DEA-Malmquist index to measure the dynamic trend of China's total factor productivity (TFP) and analyzing the underlying drivers, and (3) using a combination of remote sensing GIS technology, the DEA-Malmquist index, and a panel data model to design an interdisciplinary 
research method to explore the urban spatial form and determine the relationship between urban spatial form and TFP.

\section{Materials and Methods}

\subsection{Indicators of Urban Spatial Structure}

There is no uniform standard to measure the urban spatial form, and different indexes have been presented in various studies [24]. The spatial form of a city is usually irregular, which makes it difficult for the geometric method of regular graphics to accurately quantitatively analyze the irregular boundary form. Therefore, a large number of studies on the evaluation of urban spatial morphology use qualitative descriptions. Although this description is more illustrative, it cannot be applied to the quantitative analysis of the model, and therefore it is difficult to make quantitative comparisons. Quantitative comparison includes quantitative analysis of urban environmental conditions, structures, and functions in the form of variables, as well as dynamic analysis of morphology in time series. With the continuous development of computer and GIS technology, the quantitative evaluation of urban morphology has developed rapidly. Urban spatial structure is multifaceted and includes the following dimensions: sprawled, compact, decentralized, and polycentric. This study only focused on the dimensions of compactness and elongation, which can effectively measure the agglomeration and expansion of urban spatial structures. The index was calculated according to the formula proposed by Cole [25], in which the shape characteristics of a city are evaluated based on the minimum circumferential circle. The specific formula is as follows:

$$
\text { Compactness }=\alpha / \alpha^{\prime}
$$

where $\alpha$ is the area of the urban region and $\alpha^{\prime}$ is its smallest circumferential area. The formula takes the minimum circumferential circle as the criterion, and the maximum value is 1 . The higher the value, the higher the compactness of the city. This index is currently the most widely used in evaluating urban compactness. According to the formula, the built-up urban area is chosen as $\alpha$, which includes all municipal public facilities, concentrated areas, and surrounding suburbs that are closely related to the city. This can effectively include the urbanization area within any municipal administrative region in China.

Another important measure of urban form is the spread of the city. With the deepening of urbanization, along with the extension of the urban traffic network, cities continue to expand. Elongation is an index used to measure the extent of urban land expansion, which can effectively reflect the spread of the urban form [26]. The formula is as follows:

$$
\text { Elongation }=\beta / \beta^{\prime}
$$

where $\beta$ refers to the longest axis length of urban land, and $\beta^{\prime}$ refers to the shortest axis length. The higher the degree of expansion of urban areas, the greater the value of urban extension.

In this study, Landsat TM (Thematic Mapper) and Landsat OLI (Operational Land Imager) remote sensing images of corresponding years are selected as data sources. The image quality is good, and there is no cloud cover. The images are interpreted using ENVI5.3 and ArcGIS 10.2 software. First, the texture, size, color, and other features of the ground objects are assessed. This is necessary to grasp the spectral characteristics of the remote sensing images and compare basic information among them. The results show that the Landsat OLI image has two more bands than the Landsat TM image. However, the common band function is the same. The band combination of reddish, red, and green is not only similar to natural colors but also rich in information, which can fully show the differences in various image features. It has outstanding advantages in distinguishing between urban and rural land, and between land and water. Therefore, the aforementioned band combination is used to distinguish the built-up area and the non-built-up area. After that, the remote sensing image is transformed by 
projection, with the help of the administrative region boundary file of the representative city, the remote sensing image is spliced and clipped, and the data preprocessing is completed.

Urban construction land information extraction is the most important step in completing the index calculation. In this study, the ISODATA (Iterative Self Organizing Data Analysis) algorithm of unsupervised classification is adopted, and the post-processing of image classification is completed by visual interpretation. In the post-processing, small spots are removed or re-classified by sieve and clump. Finally, we evaluate the accuracy of the classification results. In the process of accuracy evaluation, with the help of Google Earth, urban thematic maps, and visual discrimination results. The overall classification accuracy and kappa coefficient are calculated by a confusion matrix, and the accuracy of the classification results is found to be acceptable.

\subsection{DEA-Malmquist Index}

We measure TFP using the Malmquist index based on the DEA model. This method allows the research object to have a state of technical inefficiency and does not need to assume any form of the production function, nor does it need to set estimation parameters. It is suitable for various forms of input and output and has high practicability. The Malmquist index based on the DEA model is also widely used [27-29]. The first step is to calculate the distance function using DEA, and then calculate and decompose the Malmquist index using the distance function. The distance function can compare multi-input and multi-output production techniques under unconstrained conditions, analyze the change and decrease of the input vector under the given output vector, and use the input distance function to characterize the technical features. The Malmquist productivity index is based on the benchmark technology. Technology T is the reference. The Malmquist indices for the $t$ and $t+1$ reference technologies are:

$$
\begin{aligned}
M^{t}\left(x^{t+1}, y^{t+1}, x^{t}, y^{t}\right) & =\frac{D^{t}\left(x^{t+1}, y^{t+1}\right)}{D^{t}\left(x^{t}, y^{t}\right)} . \\
M^{t+1}\left(x^{t+1}, y^{t+1}, x^{t}, y^{t}\right) & =\frac{D^{t+1}\left(x^{t+1}, y^{t+1}\right)}{D^{t+1}\left(x^{t}, y^{t}\right)} .
\end{aligned}
$$

where $\left(x^{t+1}, y^{t+1}\right)$. and $\left(x^{t}, y^{t}\right)$ represent the input and output vectors of $t+1$ and $t$, respectively. $D^{t+1}\left(x^{t+1}, y^{t+1}\right)$ and $D^{t}\left(x^{t+1}, y^{t+1}\right)$ represent $t+1$ given the input-output combination $\left(x^{t+1}, y^{t+1}\right)$ and the distance function with reference to technique $\mathrm{T}+1$ and technique T. $D^{t+1}\left(x^{t}, y^{t}\right)$ and $D^{t}\left(x^{t}, y^{t}\right)$ represent the distance function of the $t$-phase input-output combination $\left(x^{t}, y^{t}\right)$ with respect to the two-stage technical front. According to the above four distance functions, the Malmquist index of the productivity change from $t$ to $t+1$ is obtained as follows:

$$
M^{t}\left(x^{t+1}, y^{t+1}, x^{t}, y^{t}\right)=\sqrt{\frac{D^{t+1}\left(x^{t+1}, y^{t+1}\right)}{D^{t+1}\left(x^{t}, y^{t}\right)} \times \frac{D^{t}\left(x^{t+1}, y^{t+1}\right)}{D^{t}\left(x^{t}, y^{t}\right)}}
$$

Further decomposition can be obtained:

$$
M^{t}\left(x^{t+1}, y^{t+1}, x^{t}, y^{t}\right)=\frac{D^{t+1}\left(x^{t+1}, y^{t+1}\right)}{D^{t}\left(x^{t}, y^{t}\right)} \sqrt{\frac{D^{t}\left(x^{t+1}, y^{t+1}\right)}{D^{t+1}\left(x^{t+1}, y^{t+1}\right)} \times \frac{D^{t}\left(x^{t}, y^{t}\right)}{D^{t+1}\left(x^{t}, y^{t}\right)}}=\mathrm{EC} \times \mathrm{TC}
$$

In the above formula, the first part is efficiency change $(E C)$, and the second part is the rate of technology change (TC). Decomposing EC again can yield pure efficiency change (PEC) and scale efficiency change $(S E C)$, resulting in:

$$
M^{t}\left(x^{t+1}, y^{t+1}, x^{t}, y^{t}\right)=E C \times T C=(P E C \times S E C) \times T C
$$

Therefore, the decomposition of the Malmquist Productivity Index is as follows (see Figure 1): 


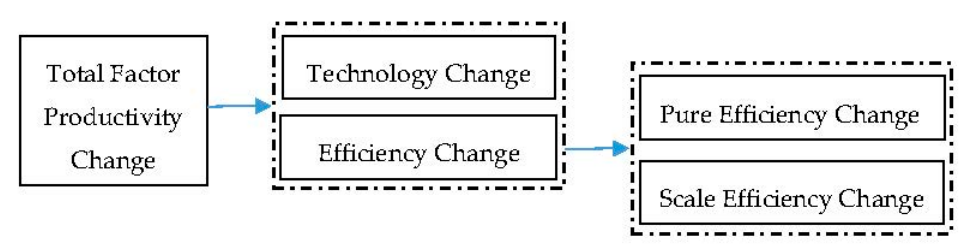

Figure 1. Decomposition of the Malmquist productivity index.

\subsection{Variable Selection and Model Setting}

\subsubsection{Explanatory Variables and Research Hypotheses}

Based on the literature review, it is found that research on TFP at home and abroad focuses mainly on opening up, human capital, technology level, government intervention, and other aspects, but it rarely involves research regarding the relationship between urban form (urban compactness and urban elongation) and TFP. Because of the differences in index selection, research methods, research objects, and research period, there are differences in the conclusions of studies, which are sometimes even contrary to each other. Based on the existing body of research, this study selects the influencing factors as follows.

\section{City Compactness}

The idea of the "compact city" [30], which originated from the concept of the "compact and mixed-use" city, was originally proposed and applied in European and American countries due to the impact of urban sprawl. Urban disordered development, ecological unsustainability, waste of land resources, and other phenomena have been criticized. In the process of urban development, the development of compact cities is considered to be an effective way to improve the comprehensive performance of cities [31]. Many researchers use GIS technology and remote sensing data to measure urban compactness and urban sprawl [32-34]. In this study, city compactness is taken as the core explanatory variable for several reasons. First, reasonable urban compactness is conducive to the intensive use of land resources and improving the production and utilization rate of land $[35,36]$. Second, the more perfect the traffic per unit area, the more compact the city, and the shorter the commuting time, the more conducive it is to the improvement of production efficiency [14]. Third, with the increase of urban compactness, the operating cost of the city will decrease, which is conducive to economic development [35]. Based on the above analysis, we propose the first hypothesis.

Hypothesis 1 (H1). There is a significant positive correlation between urban compactness and urban TFP, that is, the improvement of urban compactness has a significant role in promoting urban TFP.

\section{Urban Elongation}

Urban sprawl has become a hot issue in urban development in recent years. Rapid urban expansion is accompanied by the continuous expansion of the urban radius, and urban expansion is closely related to the urban economy [37]. At the same time, urban sprawl has also brought many negative impacts, such as increased commuting time, wasted land resources (the decrease of cultivated land and wetland), increased per capita public facilities' costs, the decline of the central urban area, and the aggravation of environmental pollution [38]. Urban elongation is an important indicator of urban sprawl, and based on the previous analysis, we put forward the second hypothesis.

Hypothesis 2 (H2). There is a significant negative correlation between urban elongation and urban TFP, that is, the larger the urban elongation, the higher the economic cost of urban development, which has a restraining effect on urban TFP. 


\subsubsection{Control Variables}

This study investigates the impact of urban form on TFP. In addition, based on the literature, it proposes several other factors that affect TFP.

Human Capital

According to the Cobb-Douglas production function, the input of the labor force will have a boosting effect on the economy. From the perspective of population scale, the larger the population, the larger the city scale, the richer the human capital, and the more the labor participating in economic activities and promoting economic development. Zhang and Xie [39] believe that population growth has a long-term positive impact on urban expansion, and urban expansion and economic development are most affected by the structure of population growth. Therefore, to control the impact of urban population size differences on TFP, this study sets human capital as a control variable and selects the number of employees to measure the city's human capital.

\section{Urban Area}

Due to the rapid development of the city, the radius of the city constantly expands and the built-up urban area significantly increases, which will inevitably increase the consumption of land resources. Research by Maimaiti et al. [40] shows that urban expansion will lead to a large loss of cultivated land and unused land. Therefore, the built-up area of the city is also set as one of the control variables in this study, and the proportion of the built-up area to the total urban area is used as the relevant measurement index.

Fiscal Expenditure

The development of the urban economy is inseparable from the macro-control of the government. Fiscal expenditure is a means of government intervention in the economy. Fiscal expenditure can not only reflect the financial concentration but also reflect the actual use and control of GDP. In the existing research on the relationship between government regulation and TFP, $\mathrm{Xu}$ [41] believes that fiscal expenditure can effectively improve TFP. Thus, this study selects fiscal expenditure as the control variable and uses the proportion of fiscal expenditure to GDP as the relevant measurement index.

\section{Research and Development Investment}

This study considers that the technological level of a city can be described in terms of dimensions such as R\&D investment, number of researchers, and number of patents. Based on the availability of data, this study selects R\&D investment as the control variable. In terms of R\&D investment, most scholars believe that scientific and technological progress can significantly promote urban TFP, and scientific and technological progress is closely related to R\&D investment and a large number of researchers' investments. Anik et al. [42] believe that technological capital is the main driver of agricultural TFP growth. Chen et al. [43] found that R\&D can effectively promote the improvement of TFP in the aquatic product processing industry. In recent years, China's sustained investment in scientific research funds has indeed brought remarkable progress in the field of science and technology.

\subsubsection{Model Setting and Variable Description}

Based on the above hypotheses, this study selects seven indicators-urban form (urban compactness and urban elongation), population scale, urban built-up area, fiscal expenditure, $R \& D$ expenditure, and foreign direct investment-for empirical research from the factors that remain controversial. We take TFP as the explained variable, and the data are estimated by DEAP (Data envelopment analysis program) 2.1 software. The data are the growth index of the year compared to that of the previous year, which cannot be directly used as the explained variable. The TFP of the first year is taken as the benchmark, and the TFP of the current year can be obtained by multiplying it every subsequent year. See Table 1 for the specific setting of the indicators. 
Table 1. List of variable indexes.

\begin{tabular}{|c|c|c|c|c|}
\hline Variable Type & Variable Name & Code & Measurement Method & Data Sources \\
\hline Explained Variable & Total Factor Productivity & $\mathrm{tfp}$ & See Formula (7) & DEAP 2.1 Estimation \\
\hline \multirow[t]{2}{*}{ Explanatory Variable } & City Compactness & cpt & See Formula (1) & $\begin{array}{l}\text { Landsat TM and Landsat OLI } \\
\text { remote sensing images; Google } \\
\text { Earth, urban thematic map }\end{array}$ \\
\hline & Urban Elongation & elg & See Formula (2) & $\begin{array}{l}\text { Landsat TM and Landsat OLI } \\
\text { remote sensing images; Google } \\
\text { Earth, urban thematic map }\end{array}$ \\
\hline \multirow{4}{*}{ Control Variable } & Number of Employees & $\mathrm{lbr}$ & $\begin{array}{c}\text { Number of employees/Total } \\
\text { population at the end of the year }\end{array}$ & \multirow{4}{*}{$\begin{array}{c}\text { China Urban Statistical } \\
\text { Yearbook/China Statistical } \\
\text { Yearbook }\end{array}$} \\
\hline & Built Up Area & bua & Built up area/total urban area & \\
\hline & Fiscal Expenditure & epd & Local budget expenditure/GDP & \\
\hline & R\&D & $\mathrm{rd}$ & Scientific expenditure/GDP & \\
\hline
\end{tabular}


The panel data model includes two dimensions: section and time. Let $i(i=1, \ldots, \mathrm{N})$ represent section (individual) and $t(t=1, \ldots, \mathrm{T})$ represent time, and then set the following linear model:

$$
Y_{i t}=\alpha_{i}+\lambda_{t}+X_{i t} \beta+\epsilon_{i t}
$$

where $Y_{i t}$ is the explained variable; $X_{i t}$ represents the explanatory variables; $\epsilon_{i t}$ is the model error term; $\beta$ is the parameter to be estimated, which indicates the marginal effect of $X_{i t}$ on $Y_{i t} ; \alpha_{i}$ is the individual effect, which refers to the influencing factors that do not change with time; and $\lambda_{t}$ represents the time effect. The panel data model can be divided into a fixed-effect model and random-effect model. When $\alpha_{i}$ and $X_{i t}$ are correlated, $\operatorname{corr}\left(\alpha_{i}, X_{i t}\right) \neq 0$, and the model is a fixed-effect model; otherwise, it is a random-effect model. This study takes 2000, 2007, 2010, and 2016 as the research periods to conduct empirical research on the relationship between TFP and urban form. Panel data combine "section data" and "time-series data". Using a panel data model has more advantages than using only a cross-sectional data model or a time-series data model. For example, a panel data model has strong control over individual heterogeneity [44], and it can involve more data points for analysis, which can reduce collinearity and increase freedom [45]. In addition, to avoid the influence of heteroscedasticity and nonstationarity, all variables need to be logarithmically transformed in a panel data regression [46]. From the perspective of previous research methods, most of the studies use the panel data model $[9,14]$. Therefore, this study also uses a panel data model. To more accurately examine the impact of urban form on TFP, this study conducts empirical research through multiple models, as shown in Table 2.

Table 2. Model summary.

\begin{tabular}{|c|c|c|c|}
\hline Category & Variable & Model & Number \\
\hline \multirow{3}{*}{$\begin{array}{c}\text { Explanatory Variable } \\
\text { Model }\end{array}$} & cpt & $\ln t f p_{i, t}=\beta_{0}+\beta_{1} \operatorname{lncpt} t_{i, t}+\varepsilon_{i, t}$ & A \\
\hline & elg & $\ln t f p_{i, t}=\beta_{0}+\beta_{1} \operatorname{lnelg}_{i, t}+\varepsilon_{i, t}$ & B \\
\hline & cpt, elg & $\begin{array}{c}\ln t f p_{i, t}= \\
\beta_{0}+\beta_{1} \ln c p t_{i, t}+\beta_{2} \operatorname{lnelg}_{i, t}+\varepsilon_{i, t} .\end{array}$ & $\mathrm{C}$ \\
\hline \multirow{3}{*}{$\begin{array}{l}\text { Explanatory and Control } \\
\text { Variable Models }\end{array}$} & cpt, lbr, bua, epd, rd & $\begin{array}{c}\operatorname{lntfp_{i,t}}= \\
\beta_{0}+\beta_{1} \operatorname{lncpt} t_{i, t}+\beta \text { ControlX } \\
i, t\end{array}$ & $\mathrm{D}$ \\
\hline & elg, lbr, bua, epd, rd & 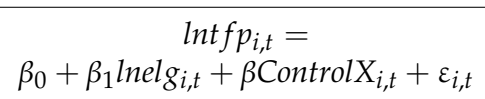 & $\mathrm{E}$ \\
\hline & cpt, elg, lbr, bua, epd, rd & $\begin{array}{c}\operatorname{lntfp_{i,t}}=\beta_{0}+\beta_{1} \operatorname{lncpt}_{i, t}+ \\
\beta_{2} \operatorname{lnelg}_{i, t}+\beta \text { ControlX } \\
i, t+\varepsilon_{i, t}\end{array}$ & $\mathrm{~F}$ \\
\hline
\end{tabular}

Among the above models, $\ln t f p_{i, t}, \operatorname{lncpt} t_{i, t}$, and $\ln \lg _{i, t}$ represent the TFP, compactness, and elongation of city $i$ in year $t$, respectively. Control $X_{i, t}$ represents each control variable of city $i$ in year $t$, such as $\operatorname{lnpop}_{i, t}, \operatorname{lnbua}_{i, t}, \operatorname{lnepd}_{i, t}$, $\ln r d_{i, t}$, and $\ln f d i_{i, t} . \varepsilon_{i, t}$ represents a random error item.

\section{Results and Analysis}

\subsection{Efficiency Distribution Characteristics of 30 Provincial Cities across the Country}

Based on input-oriented measures, the total factor productivity change index and its decomposition data of 30 provincial cities in China were measured using DEAP 2.1 software, as shown in Tables 3 and 4 . 
Table 3. Characteristics of efficiency distribution in 30 provincial cities.

\begin{tabular}{|c|c|c|c|c|c|}
\hline City & EC & TC & PEC & SEC & TFPC \\
\hline Beijing & 1 & 1.105 & 0.931 & 1.074 & 1.105 \\
\hline Tianjin & 0.91 & 0.95 & 0.93 & 0.978 & 0.864 \\
\hline Shijiazhuang & 1 & 1.231 & 1 & 1 & 1.231 \\
\hline Taiyuan & 0.945 & 0.872 & 1.007 & 0.939 & 0.825 \\
\hline Hohhot & 0.996 & 0.812 & 1.015 & 0.982 & 0.809 \\
\hline Shenyang & 0.95 & 0.829 & 0.949 & 1.002 & 0.788 \\
\hline Changchun & 0.953 & 0.839 & 0.954 & 0.999 & 0.8 \\
\hline Harbin & 0.948 & 0.776 & 0.944 & 1.004 & 0.736 \\
\hline Shanghai & 0.779 & 0.943 & 0.818 & 0.952 & 0.734 \\
\hline Nanjing & 0.988 & 0.919 & 0.994 & 0.993 & 0.908 \\
\hline Hangzhou & 0.93 & 0.894 & 0.937 & 0.992 & 0.831 \\
\hline Hefei & 0.821 & 0.705 & 0.778 & 1.055 & 0.579 \\
\hline Fuzhou & 0.89 & 0.832 & 0.904 & 0.984 & 0.74 \\
\hline Nanchang & 0.951 & 0.771 & 0.997 & 0.953 & 0.733 \\
\hline Ji'nan & 1.066 & 0.871 & 1.083 & 0.983 & 0.928 \\
\hline Zhengzhou & 0.879 & 0.813 & 0.9 & 0.977 & 0.715 \\
\hline Wuhan & 0.897 & 0.811 & 0.919 & 0.976 & 0.728 \\
\hline Changsha & 0.963 & 0.751 & 0.961 & 1.002 & 0.723 \\
\hline Guangzhou & 1 & 0.884 & 1 & 1 & 0.884 \\
\hline Nanning & 0.873 & 0.703 & 0.88 & 0.992 & 0.614 \\
\hline Haikou & 0.838 & 0.857 & 1 & 0.838 & 0.718 \\
\hline Chongqing & 0.999 & 0.679 & 0.908 & 1.099 & 0.678 \\
\hline Chengdu & 0.979 & 0.813 & 0.95 & 1.03 & 0.796 \\
\hline Guiyang & 0.983 & 0.745 & 1.057 & 0.93 & 0.732 \\
\hline Kunming & 0.824 & 0.707 & 0.847 & 0.973 & 0.583 \\
\hline Xi'an & 1.04 & 0.805 & 1.057 & 0.984 & 0.837 \\
\hline Lanzhou & 1.032 & 0.832 & 1.177 & 0.876 & 0.859 \\
\hline Xining & 0.849 & 0.755 & 0.904 & 0.939 & 0.642 \\
\hline Yinchuan & 0.807 & 0.807 & 1.037 & 0.778 & 0.651 \\
\hline Urumqi & 0.942 & 0.956 & 1.016 & 0.928 & 0.901 \\
\hline mean & 0.934 & 0.842 & 0.962 & 0.974 & 0.789 \\
\hline
\end{tabular}

Table 4. Statistics on the distribution of the mean value of TFP in 30 provincial cities.

\begin{tabular}{ccccccc}
\hline Indicator & Minimum & Maximum & Mean & $\begin{array}{c}\text { Std. } \\
\text { Dev. }\end{array}$ & $\begin{array}{c}\text { Number of Cities } \\
\text { Greater than 1 }\end{array}$ & $\begin{array}{c}\text { Efficiency City } \\
\text { Weight (\%) }\end{array}$ \\
\hline EC & 0.779 & 1.066 & 0.934 & 0.075 & 3 & 10.00 \\
TC & 0.679 & 1.231 & 0.842 & 0.116 & 2 & 6.67 \\
PEC & 0.778 & 1.117 & 0.962 & 0.081 & 8 & 26.67 \\
SEC & 0.778 & 1.099 & 0.974 & 0.063 & 7 & 23.33 \\
TFPC & 0.579 & 1.231 & 0.789 & 0.140 & 2 & 6.67 \\
\hline
\end{tabular}

According to Table 3, the largest TFP change index is in Shijiazhuang, which has reached $23.1 \%$, and the largest decline is in Hefei, which has reached $-42.1 \%$. Regarding the underlying reasons, one is technological progress, the other is the improvement of the economic system [47]. Technological progress is the root of TC, which is measured by R\&D investment and technology introduction. The improvement of the economic system is the root of EC, which is embodied in China's transformation from a planned economy to a market economy. The transformation of the economic system is generally carried out from four aspects: the rationalization of the relationship between government and market, the development of non-state economy, the degree of economic opening to the outside world, and the cultivation of the product market [47]. Based on the above analysis, it is because of the influence of technology introduction $(T C=1.231)$ that the TFPC in Shijiazhuang has risen to the highest level. Meanwhile, the double decline of Hefei's technology change index (TC = $0.705)$ and the efficiency change index $(\mathrm{EC}=0.821)$ shows that Hefei is seriously deficient in technology 
level improvements and technology introduction and lags behind in economic system improvement. Therefore, the TFPC of Hefei is greatly reduced.

According to Table 4 , the level of technological improvement in the 30 provincial cities across China is very uneven, with great differences among regions. It was found that TFPC improved in only two cities, accounting for $6.67 \%$. After decomposing TFPC, only two cities have achieved an improvement of TC, and only three cities have achieved an improvement of EC. Overall, the cities improved by TFPC are exactly the same as those improved by TC, both of which are Beijing and Shijiazhuang. This shows that the improvement of TFP in these two cities is mainly due to the improvement of technology and then the improvement of efficiency change index. For the 30 cities, the mode of economic growth needs to be further improved and adjusted. For cities with a low TFPC index, this means that the improvement of TC and EC has not led to a general atmosphere of improvement.

\subsection{Spatiotemporal Analysis of TFP and Urban Form}

According to Table 5, it can be seen that there are great differences between the minimum and maximum values of TFP in different cities, indicating that the TFP of each city for each period in each region fluctuates greatly. Furthermore, there is a large space for variation and interpretation, indicating that the regional and time differences of TFP between cities are obvious, so a panel data model is more suitable. The average value of TFP first increased and then decreased, from 0.551 in 2000 to 0.957 in 2010 and then from 0.957 in 2010 to 0.921 in 2016, showing that the TFP of each city is in a fluctuating state. According to the decomposition of TFP, it is determined mainly by the technical level and efficiency factors. This is similar to finding from Li et al. [48] and Guo and Jia [49].

Table 5. Statistical Description of Variables.

\begin{tabular}{ccccccccc}
\hline Year & Statistics & tfp & cpt & elg & lbr & bua & epd & rd \\
\hline \multirow{2}{*}{2000} & Mean & 0.551 & 0.179 & 1.767 & 0.569 & 0.118 & 0.068 & $7.27 \times 10^{-4}$ \\
& Std. Dev. & 0.230 & 0.070 & 0.648 & 0.157 & 0.082 & 0.028 & 0.001 \\
& Min & 0.206 & 0.070 & 1.060 & 0.105 & 0.018 & 0.020 & $3.45 \times 10^{-5}$ \\
& Max & 1.250 & 0.343 & 4.014 & 1.137 & 0.365 & 0.131 & 0.003 \\
\hline \multirow{2}{*}{2007} & Mean & 0.859 & 0.206 & 4.073 & 0.624 & 0.133 & 0.110 & 0.003 \\
& Std. Dev. & 0.238 & 0.083 & 3.172 & 0.366 & 0.097 & 0.031 & 0.002 \\
& Min & 0.511 & 0.095 & 1.609 & 0.090 & 0.020 & 0.069 & $6.49 \times 10^{-4}$ \\
& Max & 1.664 & 0.447 & 16.988 & 2.382 & 0.410 & 0.186 & 0.010 \\
\hline \multirow{2}{*}{2010} & Mean & 0.957 & 0.182 & 1.605 & 0.617 & 0.154 & 0.128 & 0.003 \\
& Std. Dev. & 0.114 & 0.058 & 0.708 & 0.151 & 0.112 & 0.037 & 0.003 \\
& Min & 0.523 & 0.067 & 1.030 & 0.085 & 0.033 & 0.084 & $1.03 \times 10^{-3}$ \\
& Max & 1.170 & 0.283 & 5.097 & 0.909 & 0.445 & 0.223 & 0.013 \\
\hline & Mean & 0.921 & 0.210 & 9.126 & 0.695 & 0.140 & 0.157 & 0.004 \\
& Std. Dev. & 0.116 & 0.129 & 14.850 & 0.169 & 0.094 & 0.041 & 0.004 \\
& Min & 0.662 & 0.012 & 1.855 & 0.096 & 0.031 & 0.099 & $1.20 \times 10^{-3}$ \\
& Max & 1.110 & 0.539 & 84.370 & 0.988 & 0.452 & 0.250 & 0.016 \\
\hline
\end{tabular}

In this study, urban compactness and urban elongation are measured using remote sensing GIS technology, and the analysis data of the relevant indicators are as mentioned above. In Figure 2, two cities, Zhengzhou and Lanzhou, are selected as urban compactness calculation examples based on 2010 data.

According to Table 5, with the passage of time, the compactness of each city also changes. The whole process of change is a fluctuating one, showing an average trend of first rising, then falling, and then rising again. That is, the average compactness of each city increased from 0.179 in 2000 to 0.206 in 2007. However, with the expansion and spread of cities, the average compactness of cities decreased from 0.206 in 2007 to 0.182 in 2010. After a new round of urban compact development, the average urban compactness rose from 0.182 in 2010 to 0.210 in 2016, again showing an upward 
trend. That is to say, urban compactness is a fluctuating and rising process, which is consistent with the findings of Gong [50].

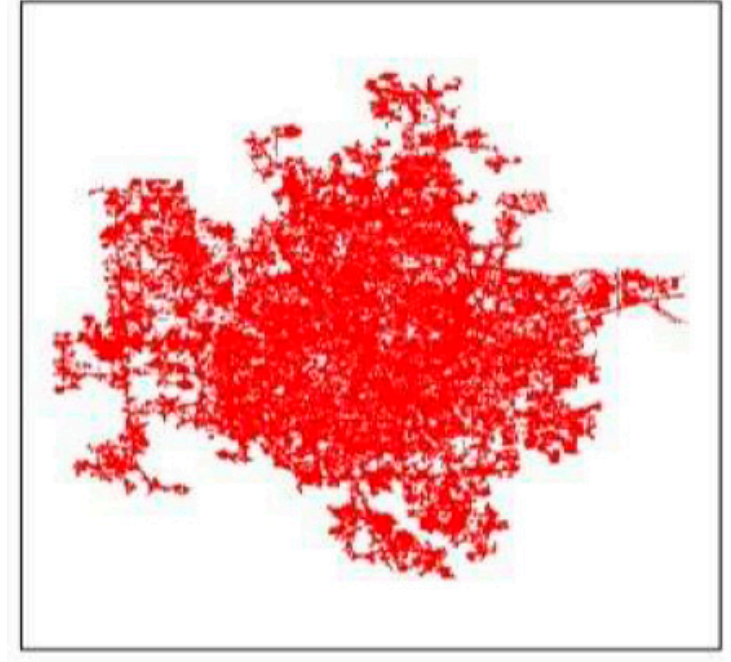

Zhengzhou (2010)

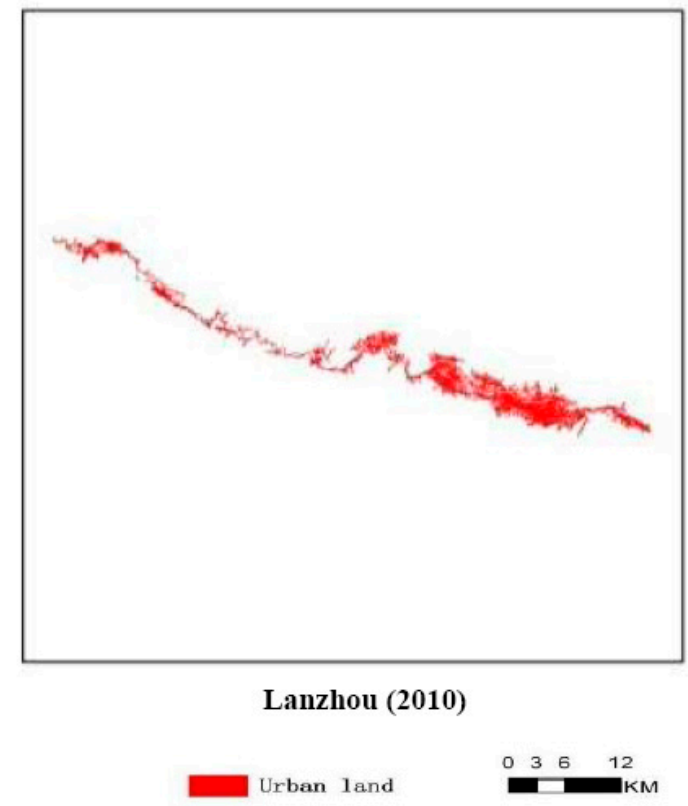

Figure 2. Calculation example of urban compactness.

Taking 2000 as the research base period, the urban compactness of each city is relatively low, indicating that urban construction is scattered and the distributions of population, land use, and transportation facilities are not centralized. However, with the passage of time and due to urban expansion and spread, the average value of urban compactness fluctuates and rises. However, due to the differences in economic conditions, resource endowments, and geographical environment, the compactness of each city is different.

As shown in Figure 3, four representative cities in eastern (Shanghai), southern (Guangzhou), western (Chongqing), and northern (Shenyang) China are listed. The compactness of Shenyang and Shanghai is found to be fluctuating over time. This shows that the improvement in the urbanization level makes the focus of urban development more concentrated, and the urban structure shows better compactness. At the same time, it can also improve the utilization rate of urban resources and effectively improve the economic situation of the city. However, the compactness of Chongqing and Guangzhou first increased and then decreased, showing that the compactness reached its maximum in 2010 and then began to decline. This may be related to the rapid development of the city. Due to the advantages of national strategic positioning, economic foundation, industrial structure, scientific and technological innovation, and other conditions, the city can rapidly promote the urbanization process, resulting in the continuous expansion of its urban radius and the gradual decline of the city's compactness.

According to Table 5, the urban elongation rate is also changing over time. The whole process of change is again a fluctuating one. It shows a trend of first rising, then falling, and then rising. That is, the average elongation rate of each city increased from 2000 (1.767) to 2007 (4.073), with the urban boundary and the scale of the city both expanding. However, with the compact development of the city, the average urban elongation rate dropped from 4.073 in 2007 to 1.605 in 2010, reflecting the compact development stage of the city. After a new round of urban expansion development, the average urban elongation rate rose from 2010 (1.605) to 2016 (9.126), again showing an upward trend. The extent of urban sprawl and expansion is very obvious. The average urban elongation rate in 2016 (9.126) is more than five times the 2010 average (1.605), which shows that the urban radius of provincial cities in China is expanding rapidly. Figure 4 shows the calculation examples of urban elongation, taking Chongqing and $\mathrm{Xi}^{\prime}$ an in 2010 as examples. 

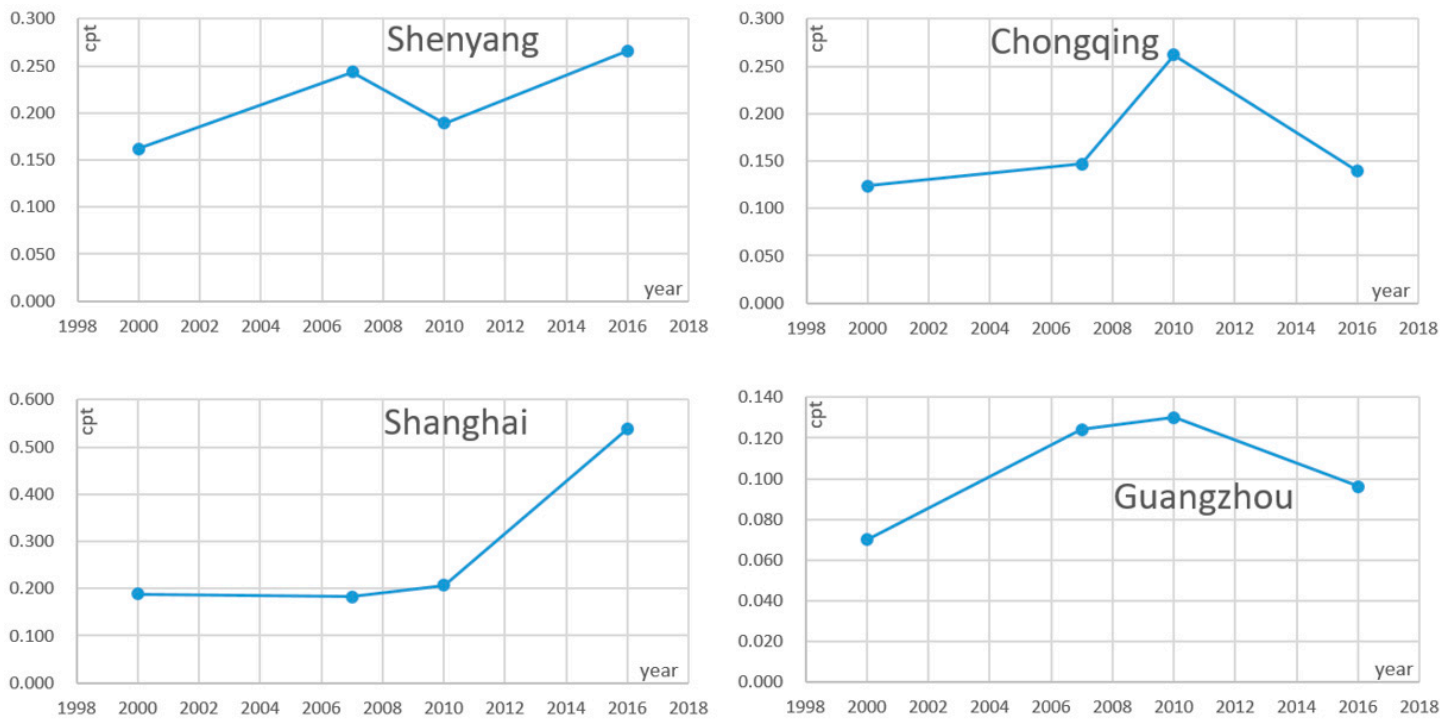

Figure 3. Trend of compactness of representative cities.

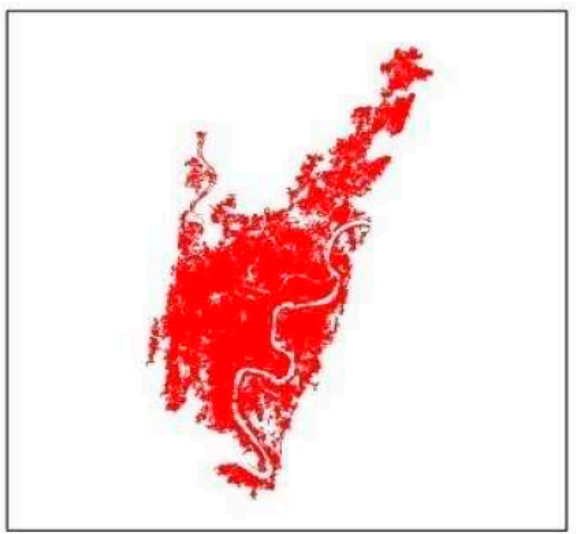

Chongqing (2010)

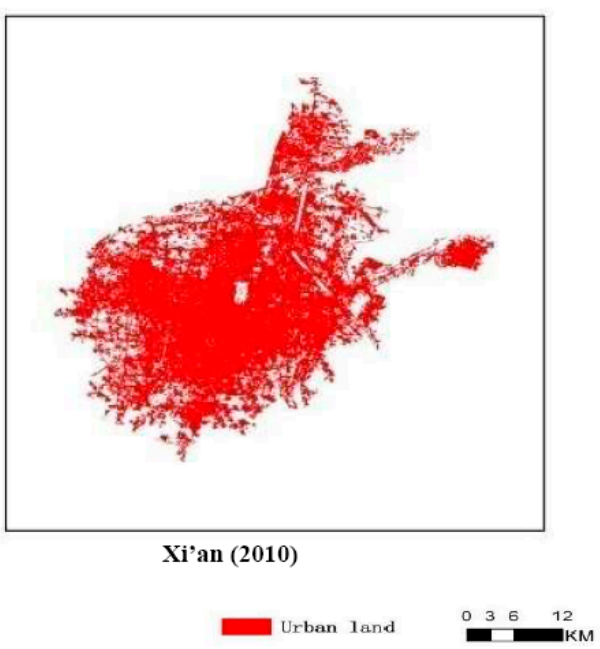

Figure 4. Calculation example of urban elongation.

Using the same representative cities mentioned above, it is found that the fluctuation of urban elongation is almost the same (see Figure 5). Each city experiences a dynamic fluctuation process of first rising, then falling, and then rising again, but the elongation intensity of each city is different. This is similar to the findings of Wang et al. [51]. According to Shi and Shi [52], the reasons may include factors such as economic development, policy support, technology improvement, planning and layout, and historical origin.

In addition, it can be seen from Table 5 that there are great differences in financial expenditure and R\&D investment between provinces and cities in China, and the difference between the minimum and maximum values is great. This is mainly because of China's vast land area and the imbalance of economic and social development levels in the eastern, central, and western regions. Although the extreme values of these two variables are obviously different, from the time series, their average values gradually rise from 2000 to 2016, which shows that the average levels of financial expenditure and $R \& D$ investment of each city have experienced a transition from small to large, and from weak to strong. The average value of fiscal expenditure (epd) increased from 0.068 in 2000 to 0.157 in 2016. This is mainly a result of the Chinese government's implementation of positive fiscal policies to expand domestic demand and survive the 2008 financial crisis, thereby increasing the fiscal expenditure year 
after year. The average value of R\&D investment increased from $7.27 \times 10^{-4}$ in 2000 to 0.004 in 2016 The investment in $R \& D$ is also increasing year by year, mainly due to China's strategic deployment of independent innovation and scientific outlook on development, which is consistent with the research view of the Department of Management and Economics of Dalian University of Technology [53].
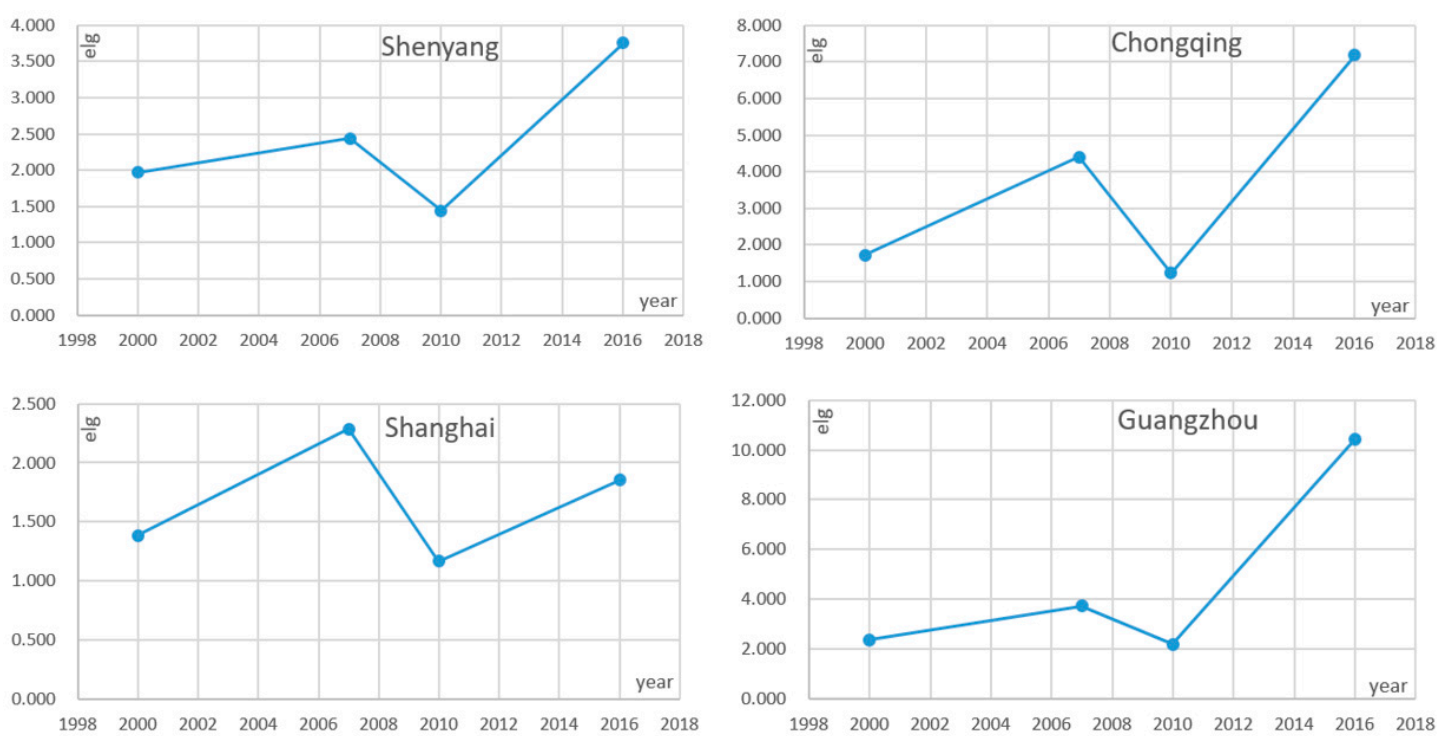

Figure 5. Urban elongation trend of representative cities.

The average built-up area increased from 0.118 in 2000 to 0.154 in 2010 and then decreased to 0.140 in 2016. The main reason is that the absolute value of the built-up area has been consistently rising. However, the formula to measure the built-up area is built-up area/total urban area, and because of the need for national management, the total urban area is dynamically adjusted over time. As the total urban area is gradually adjusted and increased, the average value of the built-up area first rises and then declines.

The average number of employees rose from 0.569 in 2000 to 0.624 in 2007, then dropped to 0.617 in 2010, and then rose again to 0.695 in 2016 . From the perspective of the fluctuation trend, only the number of employees decreased between 2007 and 2010. This is mainly due to the rise of the global unemployment rate caused by the financial crisis of 2008 [54]. In other years, China's employment situation is on the rise, reflecting a positive situation for employment.

\subsection{Impact of Urban Spatial Structure on Urban Total Factor Productivity}

It is necessary to use the Hausman test to assess whether panel data are suited to a fixed-effect model or a random-effect model. The difference between the two models is mainly reflected in the treatment of "individual effect". A fixed-effect model assumes the individual effect is fixed, and the differences between individuals are reflected in each individual having a specific intercept term. A random-effect model, meanwhile, assumes that all individuals have the same intercept term, and the differences between individuals are random, which are mainly reflected in the setting of the random interference term [55]. According to the original hypothesis of the Hausman test, the estimation results of the fixed-effect model and the random-effect model are consistent systematically. If the test results support the original hypothesis, the random-effect model should be used; if the test results reject the original hypothesis, the fixed-effect model should be selected. We conduct the Hausman test on all six models, and the results are shown in Tables 6 and 7. 
Table 6. Summary of the random-effect model results for the explanatory variables.

\begin{tabular}{cccc}
\hline & (A) & (B) & (C) \\
\hline & $\begin{array}{c}\text { lntfp } \\
\text { Random-Effect Model }\end{array}$ & $\begin{array}{c}\text { lntfp } \\
\text { Random-Effect Model }\end{array}$ & $\begin{array}{c}\text { lntfp } \\
\text { Random-Effect Model }\end{array}$ \\
\hline lncpt & $0.070(1.39)$ & & $0.001(0.02)$ \\
lnelg & & $-0.112^{* * *}(-3.91)$ & $-0.111^{* * *}(-3.60)$ \\
_cons & $-0.743^{* * *}(-5.59)$ & $-0.753^{* * *}(-7.24)$ & $-0.751^{* * *}(-5.80)$ \\
\hline Obs. & 120 & 120 & 120 \\
Within $R^{2}$ & 0.0230 & 0.1539 & 0.1539 \\
$\mathrm{R}^{2}$ & 0.8805 & 0.8965 & 0.8965 \\
Adj. $\mathrm{R}^{2}$ & 0.8402 & 0.8616 & 0.8600 \\
Hausman test & $0.21(0.8988)$ & $1.75(0.4173)$ & $2.23(0.5258)$ \\
\hline
\end{tabular}

For the random-effect models, the value in parentheses is the $\mathrm{Z}$ statistic; the value in parentheses for the Hausman test is the $p$ value. ${ }^{* * *} p<0.01,{ }^{* *} p<0.05,{ }^{*} p<0.1$.

Table 7. Summary of the random-effect model results for the comprehensive variables.

\begin{tabular}{cccc}
\hline & (D) & (E) & (F) \\
\hline & $\begin{array}{c}\text { Lntfp Fixed-Effect } \\
\text { Model }\end{array}$ & $\begin{array}{c}\text { Lntfp Fixed-Effect } \\
\text { Model }\end{array}$ & $\begin{array}{c}\text { Lntfp Fixed-Effect } \\
\text { Model }\end{array}$ \\
\hline lncpt & $0.119^{* * *}(2.68)$ & & $0.098^{* *}(1.96)$ \\
$\ln$ lg & & $-0.058^{* *}(-2.00)$ & $-0.028^{*}(-0.89)$ \\
lnlbr & $-0.093(-1.09)$ & $-0.075(-0.86)$ & $-0.086(-1.00)$ \\
lnbua & $-0.044(-0.90)$ & $-0.064(-1.27)$ & $-0.050(-1.00)$ \\
lnepd & $0.032(0.35)$ & $0.002(0.02)$ & $0.039(0.42)$ \\
lnrd & $-0.119^{* * *}(-3.43)$ & $-0.085^{* *}(-2.54)$ & $-0.111^{* * *}(-3.13)$ \\
cons & $-1.509 * *(-9.50)$ & $-1.539 * *(-9.30)$ & $-1.463 * *(-8.75)$ \\
\hline Obs. & 120 & 120 & 120 \\
Within $R^{2}$ & 0.3788 & 0.3566 & 0.3846 \\
$\mathrm{R}^{2}$ & 0.9240 & 0.9213 & 0.9247 \\
Adj. $\mathrm{R}^{2}$ & 0.8936 & 0.8898 & 0.8933 \\
Hausman test & $15.09(0.0196)$ & $18.1(0.0060)$ & $18.22(0.0110)$ \\
\hline
\end{tabular}

For the fixed-effect models, the value in parentheses is the $\mathrm{Z}$ statistic; the value in parentheses for the Hausman test is the $p$ value. ${ }^{* * *} p<0.01,{ }^{* *} p<0.05, * p<0.1$.

Table 6 reports the panel database regression model analysis results of the impact of urban compactness and urban elongation on TFP as explanatory variables. According to the Hausman test, the random-effect model is selected for the report result. At the same time, a BP-LM (Breusch and Pagan Lagrangian multiplier) test was conducted for all random-effect models ( $p$ value: 0.0000 ). The test results show that the random-effect model is better than the POLS (Pooled ordinary least squares) model; thus, the random-effect model should be used. It can be seen from Models $B$ and $C$ that urban elongation has a significant negative impact on urban TFP ( $B$ model is $\beta=-0.112, p<$ $0.01, C$ model is $\beta=-0.111, p<0.01$ ), indicating that the higher the elongation is, the more likely it is to decline. Taking Model $\mathrm{C}$ as an example, it is also found that the impact of urban elongation on urban TFP is approximately $-11.1 \%$, meaning that urban TFP decreases about $11.1 \%$ every year due to the increase of urban elongation. This shows that on the whole, urban elongation has a significant inhibitory effect on the TFP of the city, thus inhibiting economic development. From Models A and $C$, it can be seen that urban compactness promotes urban TFP, but the relationship is not significant. This may be because urban compactness is a complex problem, and urban TFP is a comprehensive reflection of urban development. It is necessary to add other control variables to further the empirical research to gain a deeper understanding of the situation. According to Model C, $R^{2}=0.8965$ and adj. $\mathrm{R}^{2}=0.8600$, which shows that when only considering the urban form, it can explain the TFP of the city to a high degree. 
Table 7 contains the regression results of Models D, E, and F. The regression results include explanatory variables and control variables together. The Hausman test uses the fixed-effect model. At the same time, for all fixed-effect models, it was found that the $p$ value of the $\mathrm{F}$ test was 0.0000 , and the test results showed that the fixed-effect model was better than the POLS model. Model D contains one explanatory variable (city compactness) and four control variables. The regression results show that there is a highly significant positive correlation between city compactness and TFP $(\beta=0.119$, $p<0.01$ ). Model E contains one explanatory variable (urban elongation) and four control variables. The regression results show that urban elongation has a significant negative correlation with TFP $(\beta=-0.058, p<0.05)$. Model F contains two explanatory variables (city compactness, city extension rate) and four control variables. It is a comprehensive model that includes all variables. The test of variance expansion factor $(\mathrm{VIF}=1.89<10$ ) shows that the variables used in the model are highly unlikely to have multiple collinearity problems. At the same time, $R^{2}=0.9247$ and adj. $R^{2}=0.8933$, which indicates that the model has a good fit and a high degree of interpretation. The regression results of Model F show that there is still a highly significant positive correlation between urban compactness and TFP $(\beta=0.098, p<0.05)$ and a significant negative correlation between urban elongation and TFP $(\beta=-0.028, p<0.1)$.

Models D, E, and F (including control variables) and Models A, B, and C (no control variables, only explanatory variables) are also compared with each other. In terms of urban compactness, there is a positive correlation between urban compactness and TFP in Models A, B, and C, but the relationship is not significant. However, Models D, E, and F, with control variables added, show a highly significant positive correlation between urban compactness and urban TFP, indicating that the relationship between urban compactness and urban TFP becomes significant under the influence of comprehensive factors. This also verifies Hypothesis 1, which asserts that the improvement of urban compactness has a significant role in promoting urban TFP. This conclusion is also consistent with Salvati [11], who found that "cities with high compactness have higher self-growth rate", and Tian and Li [56], who concluded that "urban compactness is conducive to the higher efficiency level". Regarding the aspect of urban elongation, all the models related to urban elongation show a highly significant negative correlation between urban elongation and urban TFP, indicating that the impact of urban elongation on urban TFP is very stable. This also verifies Hypothesis 2, which asserts that the larger the urban elongation, the higher the economic cost of urban development, which has a restraining effect on TFP. This is also consistent with the findings of $\mathrm{Li}$ and $\mathrm{Hu}$ [57] and Qin and Liu [58].

\section{Conclusions}

Modern urban development in China has paid attention to city size, and, indeed, there were fierce debates over the development of large cities versus medium-sized cities [59]. Subsequently, along with rapid urbanization, cities of various sizes quickly developed [60]. However, with the emergence of various urban problems and damage to the ecological environment, urban development has placed greater emphasis on economic efficiency and environmental friendliness [24].

In this study, data on the urban compactness and urban elongation of 30 provincial cities in China are measured using remote sensing GIS technology. The average values of urban compactness and urban elongation show a trend of first rising, then falling, and then rising again. This shows that the cities are expanding outward at the same time of compact development, and there are alternate situations of urban compact development and urban sprawl expansion. On the one hand, each city is developing toward a compact city, showing the phenomenon of comprehensive land utilization and efficiency improvement in public transport. On the other hand, due to urban development, planning layouts, and economic foundations, cities are also accompanied by the trend of a gradually expanding urban radius. Based on a panel data model, this study finds that there is a significant positive correlation between urban compactness and TFP $(\beta=0.098, p<0.05)$. Cities with high urban compactness have a positive effect on TFP. There is a significant negative correlation between urban elongation and TFP $(\beta=0.028, p<0.1)$, indicating that cities with high urban elongation experience 
a restraining effect on TFP. In terms of TFP, the DEA-Malmquist index is used to measure the TFPC of 30 provincial cities in China. The TFPC of only two cities has improved, accounting for $6.67 \%$. After decomposing TFPC, only two cities have achieved the improvement of TC and three cities have achieved the improvement of EC. On the whole, the cities with an improved TFPC are the same as those with an improved TC: Beijing and Shijiazhuang. This shows that the improvement of TFPC in these two cities is mainly due to the improvement of technology and then the improvement of efficiency change index. TFP is generally low, and most cities have not achieved efficiency improvement.

Therefore, policy practitioners should improve urban efficiency, especially in the promotion and introduction of technology, as well as the improvement of compact cities. Cities with high compactness have a positive effect on TFP. Although the effect on TFP cannot be observed immediately because of a temporal lag, its effectiveness can be observed in the long run [61].

Despite this study's contributions, it does have some limitations. In particular, it only provides correlations among certain urban aspects. That said, the present findings are well aligned with those of previous related studies [62]. Future research can focus on including more spatial indicators, as well as correlations of compactness and elongation coefficients.

Author Contributions: H.Y. Project administration, formal analysis, and drafting the paper. Y.L. Responsible for the model operation of the study and helped to check and revise the spelling and grammar of the paper. J.Z. Responsible for data processing in the study. G.L. Assisted with model operation for the study. All authors have read and agreed to the published version of the manuscript.

Funding: This study was supported by the National Natural Science Foundation of China $(41671515 ; 41301612)$ and the Educational and Scientific Research Project for Young and Middle-Aged Teachers in Fujian Province (JAS160761).

Acknowledgments: We thank Chunming Bo for his assistance with the figures.

Conflicts of Interest: The authors declare no conflicts of interest.

\section{References}

1. CPC Central Committee State Council. National New Urbanization Plan (2014-2020); CPC Central Committee State Council: Beijing, China, 2014; pp. 1-35.

2. Lewin, S.S. Urban Sustainability and Urban Form Metrics. J. Green Build. 2012, 7, 44-63. [CrossRef]

3. Kotharkar, R.; Bahadure, P.; Sarda, N. Measuring Compact Urban Form: A Case of Nagpur City, India. Sustainability 2014, 6, 4246-4272. [CrossRef]

4. Sveikauskas, L. The Productivity of Cities. Q. J. Econ. 1975, 89, 393-413. [CrossRef]

5. Beeson, P. Total factor productivity growth and agglomeration economies in manufacturing. J. Reg. Sci. 2006, 27, 183-199. [CrossRef]

6. Qi, W.F.; Fang, C.L.; Song, J.T. Measurement and spatial distribution of urban agglomeration industrial compactness in China. Chin. Geogr. Sci. 2008, 18, 291-299. [CrossRef]

7. Lee, B.; Gordon, P. Urban structure: Its role in urban growth, net new business formation and industrial churn. Reg. Dev. 2011, 33, 137-159.

8. Huang, Y.B.; Dong, S.C. Spatial Analysis of Urban Compactness in China. In Proceedings of the 2014 22nd International Conference on Geoinformatics, Kaohsiung, Taiwan, 25-27 June 2014.

9. Dong, W.X.; Zhu, S.L.; Guo, L.Z. A Study on Urban Compactness and Total Factor Productivity-Based on the GMM Method of Panel Data. J. Yunnan Univ. Financ. Econ. 2017, 5, 128-136.

10. Cervero, R. Efficient Urbanisation: Economic Performance and the Shape of the Metropolis. Urban Stud. 2001, 38, 1651-1671. [CrossRef]

11. Salvati, L. Urban containment in action? Long-term dynamics of self-contained urban growth in compact and dispersed regions of southern Europe. Land Use Policy 2013, 35, 213-225. [CrossRef]

12. Meijers, E.J.; Burger, M.J. Spatial structure and productivity in US metropolitan areas. Environ. Plan. A 2010, 42, 383-1402. [CrossRef]

13. Bindong, S.; Xuhui, W.; Yinyin, C. An empirical study on the economic performance of polycentric spatial structure of mega-cities in China. City Plan. Rev. 2015, 39, 39-45. 
14. Weiwei, H.; Meiqing, Z.; Zongqing, L. Empirical Study on the Relationship between Traffic, Urban Compactness and Urban Productivity*-Based on the Panel Data Analysis of Prefecture-Level Cities in Beijing, Tianjin and Hebei. Macroeconomics 2016, 1, 109-120.

15. Fare, R.; Grosskopf, S.; Norris, M.; Zhang, Z. Productivity Growth, Technical Progress, and Efficiency Change in Industrialized Countries. Am. Econ. Rev. 1994, 84, 66-83.

16. Kumar, S.; Russell, R.R. Technological Change, Technological Catch up and Capital Deepening: Relative Contribution to Growth and Convergence. Am. Econ. Rev. 2002, 92, 527-548. [CrossRef]

17. Lall, P.; Featherstone, A.M.; Norman, D.W. Productivity Growth in the Western Hemisphere (1978 1994): The Caribbean in Perspective. J. Prod. Anal. 2002, 17, 213-231. [CrossRef]

18. Kruger, J.J. The Global Trends of Total Factor Productivity: Evidence from the Nonparametric Malmquist Index Approach. Oxf. Econ. Pap. 2003, 55, 265-286. [CrossRef]

19. Yifu, L.; Peilin, L. The Effects of Development Strategy on Capital Accumulation and Technological Progress: An Empirical Analysis of Chinese Experience. Soc. Sci. China 2003, 4, 18-33.

20. Jinghai, Z.; Angang, H. An Empirical Analysis of Provincial Productivity in China (1979-2001). China Econ. Q. 2005, 4, 263-296.

21. Pengfei, Y.; Bing, W. Technical Efficiency, Technical Progress \& Productivity Growth: An Empirical Analysis Based on DEA. Econ. Res. J. 2004, 12, 55-65.

22. Hu, A.; Zheng, J.; Gao, Y.; Zhang, N.; Xu, H. Provincial Technology Efficiency Ranking With Environment Factors(1999 2005). China Econ. Q. 2008, 3, 933-960.

23. Bing, W.; Yanrui, W.; Pengfei, Y. Environmental Efficiency and Environmental Total Factor Productivity Growth in China's Regional Economies. Econ. Res. J. 2010, 5, 95-109.

24. Liu, Y.; Arp, H.P.H.; Song, X.; Song, Y. Research on the relationship between urban form and urban smog in China. Environ. Plan. B Plan. Des. 2017, 44, 328-342. [CrossRef]

25. Cole, J.P. Study of major and minor civil division in political geography. In Proceedings of the 20th International Geographical Congress, Sheffield, UK, 20-28 July 1964.

26. Haggett, P. Locational Analysis Human Geography; Edward Arnold Ltd.: London, UK, 1997; p. 309.

27. Yin, J.; Tan, Q. Study on Urban Efficiency Measurement and Spatiotemporal Evolution of Cities in Northwest China Based on the DEA-Malmquist Model. Sustainability 2019, 11, 434. [CrossRef]

28. Sahin, G.; Gokdemir, L.; Ozturk, D. Global Crisis and Its Effect on Turkish Banking Sector: A Study with Data Envelopment Analysis. In Proceedings of the 5th Istanbul Conference of Economics and Finance, Istanbul, Turky, 22-23 October 2015; Volume 38, pp. 38-48.

29. Asgari, B.; Wong, R.W.S. Total Factor Productivity Measurements: Theoretical and Empirical Analysis of Manufacturing Industry in Japan and Malaysia. In Proceedings of the Picmet 2010 Technology Management for Global Economic Growth, Phuket, Thailand, 18-22 July 2010.

30. Dantzing, G.B.; Satty, T.L. Compact City: A Plan for a Livable City Environment; W.H. Freeman: San Francisco, CA, USA, 1973.

31. Jenks, M.; Jones, C. Dimensions of the Sustainable City; Springer: London, UK, 2010; Volume 2, p. 282.

32. Poelmans, L.; Rompaey, A.V. Complexity and performance of urban expansion models. Comput. Environ. Urban Syst. 2010, 34, 17-27. [CrossRef]

33. Martellozzo, F.; Clarke, K.C. Measuring Urban Sprawl, Coalescence, and Dispersal: A Case Study of Pordenone, Italy. Environ. Plan. B Plan. Des. 2011, 38, 1085-1104. [CrossRef]

34. Inostroza, L.; Baur, R.; Csaplovics, E. Urban sprawl and fragmentation in Latin America: A dynamic quantification and characterization of spatial patterns. J. Environ. Manag. 2013, 115, 87-97. [CrossRef]

35. Jian, L.; Shuaiwei, X. The Study on Compactness Calculation and its MultipleEffects for Mega-cities in China. Urban Dev. Stud. 2016, 23, 109-116.

36. Xiafei, Y. Research on the Relationship between Urban Compactness and Urban Output Efficiency in the Yangtze River Delta. China Mark. 2017, 26, 29-30.

37. Gandhi, S.R.; Sharma, S.A.; Vyas, A. Quantifying Urban Sprawl for Rajkot City using Geospatial Technology. Int. J. Built Environ. Sustain. 2016, 3, 86-92. [CrossRef]

38. Jiating, W.; Yu, X.; Hongfu, M.; Siyuan, C. The performance of urban sprawl and its impact on ecological environment. Urban Probl. 2014, 5, 22-27. 
39. Zhang, Y.; Xie, H. Interactive Relationship among Urban Expansion, Economic Development, and Population Growth since the Reform and Opening up in China: An Analysis Based on a Vector Error Correction Model. Land 2019, 8, 153. [CrossRef]

40. Maimaiti, B.; Ding, J.L.; Simayi, Z.; Kasimu, A. Characterizing urban expansion of Korla City and its spatial-temporal patterns using remote sensing and GIS methods. J. Arid Land 2017, 9, 458-470. [CrossRef]

41. Xu, M. Empirical Study on the Effects of Fiscal Expenditure on Economic Growth Patterns of China: 1993-2008. In Proceedings of the International Conference on Economics and Social Science (ICESS 2013), Melbourne, Australia, 20-21 January 2013; Volume 14.

42. Anik, A.R.; Rahman, S.; Sarker, J.R. Agricultural Productivity Growth and the Role of Capital in South Asia (1980-2013). Sustainability 2017, 9, 470. [CrossRef]

43. Chen, T.G.; Lin, G.; Takahashi, Y.; Yabe, M. Aquatic Product Processing Industry's Total Factor Productivity an Influencing Factors in China. J. Fac. Agric. Kyushu Univ. 2018, 63, 423-431.

44. Seto, K.C.; Kaufmann, R.K. Modeling the Drivers of Urban Land Use Change in the Pearl River Delta, China: Integrating Remote Sensing with Socioeconomic Data. Land Econ. 2003, 79, 106-121. [CrossRef]

45. Hsiao, C. Analysis of Panel Data; Cambridge University Press: New York, NY, USA, 2003.

46. Niu, S.; Ding, Y.; Niu, Y.; Li, Y.; Luo, G. Economic growth, energy conservation and emissions reduction: A comparative analysis based on panel data for 8 Asian-Pacific countries. Energy Policy 2011, 39, 2121-2131. [CrossRef]

47. Zhao, Z.; Yang, C. Estimation and Explanation of China's Total Factor Productivity: 1979-2009. Res. Financ. Econ. Issues 2011, 9, 3-12.

48. Li, P.; Zhong, X.Y.; Wang, H.W.; Zheng, S.L. Productivity change and source of economic growth in China: 1978-2010. J. Quant. Tech. Econ. 2013, 1, 3-21.

49. Qingwang, G.; Junxue, J. Estimating Total Factor Productivity in China. Econ. Res. J. 2005, 6, 51-60.

50. Yao, G.X. Study on the Comprehensive Measure of Urban Compactness-A Case of Nine Cities in Pearl River Delta. Master's Thesis, Jiangxi University of Science and Technology, Nanchang, China, 2019.

51. Wang, J.; Xie, Y.; Ma, H.; Cai, S. Measuring China's urban sprawl in the rapid urbanization period by multi-indicator index method. City Plan. Rev. 2019, 6, 9-19.

52. Shouzheng, S.; Yishao, S. Multi-dimensional reflections of urban sprawl. Hum. Geogr. 2017, 4, 54-59.

53. DUT Faculty of Management and Economics. China R\&D Fund Report. Zhishifenzi 2018, 1, 1-27.

54. Fang, C. On the principle of employment priority from the influence of financial crisis. China Employ 2010, 7, 8-11.

55. Zhang, H.; Jia, Y. A New Idea for Setting PanelData Model-Unification of Fixed Effects and Random Effects. J. Quant. Tech. Econ. 2006, 23, 148-154.

56. Shi, T.C.; Jin, L. Research on the relationship between the compactness of large cities and energy efficiency. J. Nat. Resour. 2018, 33, 1781-1795.

57. Li, Q.; He, C. Urban sprawl and total factor productivity. J. Hunan Financ. Econ. Univ. 2017, 1, 33-39.

58. Meng, Q.; X, L. Does urban sprawl bring about the loss of urban productivity in China?-An Empirical Study Based on nighttime lighting data. J. Financ. Econ. 2015, 7, 28-40.

59. Zhou, X. On the Scale Policy of China's Urban Development. Manag. World 1992, 6, 166-171.

60. Wang, $X$. The Law and Development Trend of World's Big Urbanization. Urban Dev. Res. 2015, 5, 111-116.

61. Liu, Y.; Song, Y.; Arp, H. Examination of the relationship between urban form and urban eco-efficiency in China. Habitat Int. 2012, 36, 1771-1777. [CrossRef]

62. Ahlfedlt, G.; Pietrostefani, E. Demystifying Compact Urban Growth: Evidence from 300 Studies from across the World; Coalition for Urban Transitions: London, UK; Washington, DC, USA, 2017.

(C) 2019 by the authors. Licensee MDPI, Basel, Switzerland. This article is an open access article distributed under the terms and conditions of the Creative Commons Attribution (CC BY) license (http://creativecommons.org/licenses/by/4.0/). 